\title{
Electrodeposition and Characterisation of Copolymers Based on Pyrrole and 3,4-Ethylenedioxythiophene in BMIM BF4 Using a Microcell Configuration
}

\author{
Lavinia Astratine \\ University of Limerick \\ Edmond Magner \\ University of Limerick \\ John Cassidy \\ Technological University Dublin, john.cassidy@tudublin.ie
}

See next page for additional authors

Follow this and additional works at: https://arrow.tudublin.ie/scschcpsart

Part of the Medicinal-Pharmaceutical Chemistry Commons

\section{Recommended Citation \\ This Article is brought to you for free and open access by the School of Chemical and Pharmaceutical Sciences at ARROW@TU Dublin. It has been accepted for inclusion in Articles by an authorized administrator of ARROW@TU Dublin. For more information, please contact arrow.admin@tudublin.ie, aisling.coyne@tudublin.ie, gerard.connolly@tudublin.ie. \\ Funder: upported by the University of Limerick and Technological University Dublin Joint Common Interest Group Scheme, Ireland.}

Astratine, L., Magner, E., Cassidy, J., Betts, A.: Electrodeposition and Characterisation of Copolymers Based on Pyrrole and 3,4-Ethylenedioxythiophene in BMIM BF4 Using a Microcell Configuration. Electrochimica Acta, Vol.115, January, 2014, p.440-448. http://dx\# doi:10.1016/j.electacta.2013.10.198 


\section{Authors}

Lavinia Astratine, Edmond Magner, John Cassidy, and Tony Betts

This article is available at ARROW@TU Dublin: https://arrow.tudublin.ie/scschcpsart/37 


\title{
Electrodeposition and Characterisation of Copolymers Based on Pyrrole and 3,4-Ethylenedioxythiophene in BMIM BF 4 Using a Microcell Configuration
}

\author{
Lavinia Astratine $^{\mathrm{a}, 1}$, Edmond Magner ${ }^{\mathrm{a}, 1}$, John Cassidy ${ }^{\mathrm{c}, *}$, Anthony Betts $^{\mathrm{b}}$ \\ a Materials Surface and Science Institute E Department of Chemical and Environmental Sciences, University of Limerick, Limerick, Ireland \\ ${ }^{\mathrm{b}}$ Applied Electrochemistry Group, Dublin Institute of Technology, Focas Institute, Camden Row, Dublin 8, Ireland \\ ' School of Chemical and Pharmaceutical Sciences, Dublin Institute of Technology, Kevin St, Dublin 8, Ireland
}

\section{A R T I C L E I N F O}

\section{Article history:}

Received 11 October 2013

Received in revised form 25 October 2013

Accepted 30 October 2013

Available online 11 November 2013

\section{Keywords:}

Copolymer

Polypyrrole

3 ;4- ethylenedioxythiophene

1-butyl-3-methylimidazolium

tetrafluoroborate

Microcell

\begin{abstract}
A B S T R A C T
Electrochemical copolymerization of pyrrole (Py) and 3,4-ethylenedioxythiophene (EDOT) was performed in an ionic liquid 1-butyl-3-methylimidazolium tetrafluoroborate, (BMIM BF4) employing a 'micro-cell' in order to use the materials efficiently. Characterization of the copolymers formed on an ITO substrate was performed for different Py: EDOT ratios $(1: 2,1: 1,2: 1)$ in both aqueous and ionic liquid electrolytes. The three copolymers displayed different absorbance spectra with $\lambda$ max of the polaron species at 507, 540 and $580 \mathrm{~nm}$ for PPy-co-PEDOT ratios of 1:2, 1:1, 2:1, respectively. Electrochemical and spectroelectrochemical analysis revealed that the properties of the copolymer depend upon the Py/EDOT monomer ratio used. The copolymer PPy-Co-PEDOT (2:1) displayed good stability, a switching time of 20 $s$ and a colouration efficiency of $101.3 \mathrm{C}-1 \mathrm{~cm} 2$. The presence of Py in the copolymer stabilised the polaron state of the copolymer and allowed greater ion mobility compared to the PEDOT alone.
\end{abstract}

(C) 2013 Elsevier Ltd. All rights reserved.

\section{Introduction}

Conducting polymers [1] have attracted attention because of their potential applications in different fields such as supercapacitors [2], sensors [3], photovoltaic cells [4], electrochromic devices [5], organic light-emitting diodes [6], and actuators [7]. Significant progress has been made in increasing the conductivity, stability and processability of conducting polymers. Polypyrrole (PPy) has been widely employed as a conducting polymer and extensively characterized due to its high electrical conductivity, long term environmental stability and ease of synthesis by chemical or electrochemical means $[8,9]$. The polymer poly(3,4-ethylenedioxythiophene) (PEDOT) has received significant attention in applications as an organic electrochromic material because of its rapid switching time and low monomer oxidation potential [10]. Both of these conducting polymers can be formed and used in a range of solvents, aqueous or organic, and have received increased interest due to their potential in electrochromic applications [11].

\footnotetext{
* Corresponding author. Tel.: +353014024779.

E-mail addresses: lavinia.astratine@ul.ie (L. Astratine),edmond.magner@ul.ie (E. Magner), john.cassidy@dit.ie (J. Cassidy), anthony.betts@dit.ie (A. Betts).

1 Tel: +353061234168, Fax: +353061203529
}

PPy films, in particular, have generated significant interest due to their outstanding electronic and optical properties. For example, the reduced yellow form of polypyrrole film displays a maximum absorption wavelength at $400 \mathrm{~nm}$, while the fully oxidized blue/black form has a broad absorbance with a broad maximum around $800 \mathrm{~nm}$ [12]. Polypyrrole is formed in the oxidized state, $\mathrm{PPy}^{+2}$ (bipolaron state), and it can be reduced to the neutral, insulating form, $\mathrm{PPy}^{0}$. The perchlorate anion is frequently utilised for the electrochemical formation of polypyrrole films as it results in films with a high degree of uniformity and reproducibility [13].

Ionic liquids are suitable solvents for the electrodeposition of metals [14] [15] and semiconductors [16] as they possess wide electrochemical potential windows, spanning up to $6 \mathrm{~V}$ in some cases. Room temperature ionic liquids (RTILs or ILs) are known to be environmentally benign media. Their non-volatility and excellent electrochemical stability [17] are of interest as they can be used directly as hydrophobic electrolytes for the deposition of both PPy and PEDOT. ILs possess a number of desirable properties that include thermal and chemical stability, low melting point, high ionic conductivity, negligible volatility, moderate viscosity and solubility (affinity) with many compounds. They represent a 'green' alternative to many traditional electrolytes [18]. ILs containing anions such as $\mathrm{NTF}_{2}, \mathrm{BF}_{4}$ and $\mathrm{PF}_{6}$ have large electrochemical windows of stability which can go over $+2 \mathrm{~V}$ vs $\mathrm{Ag} / \mathrm{Ag}^{+}$in the oxidation region and below $\mathrm{Li} / \mathrm{Li}^{+}$potential in the reductive region [18]. 
Studies of pyrrole [8] in various ionic liquids indicate that intercalation/loss of a cation occurs rather than anion intercalation/expulsion on oxidation and reduction of the polymer. Because ionic liquids have wide electrochemical windows, during growth of polypyrrole the potentials used were higher than in conventional electrolytes [19]. In experiments conducted in 1-butyl-3methylimidazolium hexafluorophosphate (BMIM $\mathrm{PF}_{6}$ ), 1-ethyl-3-methylimidazolium bis(trifluoromethansulfonyl) amide and (N,N-butylmethylpyrrolidinium bis(trifluoromethanesulfonyl) amide, TFSA), polypyrrole films yielded increased faradaic response in comparison to PPy films prepared in an acetonitrile/ $/ \mathrm{LiClO}_{4}$ solution. The electrochemical activity of PPy was dependent on the nature of the ionic liquid employed. Increased faradaic current was more obvious when PPy films were prepared in $\mathrm{N}, \mathrm{N}-$ butylmethylpyrrolidinium TFSA, as the faradaic current appeared four times greater than in acetonitrile/ $/ \mathrm{LiClO}_{4}$ solution [8].

An improvement in the quality of polypyrrole film was achieved [20] on using the water and air stable ionic liquid 1-ethyl3-methylimidazolium trifluoromethanesulfonate (EMIM $\mathrm{CF}_{3} \mathrm{SO}_{3}$ ). Imidazolium ionic liquids, having stable counter anions such as $\mathrm{BF}_{4}{ }^{-}, \mathrm{PF}_{6}{ }^{-}$and $\mathrm{CF}_{3} \mathrm{SO}_{3}{ }^{-}$, were considered as good candidates for the polymerization process as they do not require special conditions, such as use of an inert atmosphere. The room temperature ionic liquid EMIM $\mathrm{CF}_{3} \mathrm{SO}_{3}$, when used as a medium for the electropolymerization process, resulted in faster polymerization rates and improvements in the electrochemical capacitance and electro-conductivity. This can be explained by the fact that charge neutrality during film formation was maintained by anion and cation exchange with the ionic liquid [20].

Another monomer available commercially since 1990 is 3,4ethylenedioxythiophene (EDOT) which displays many interesting properties; namely high environmental stability, high conductivity and excellent transparency in its doped state. An interesting feature of EDOT is its progressive emergence as a building block for the synthesis of different classes of molecular $\pi$ conjugated systems. Poly(3,4-ethylenedioxythiophene) (PEDOT) has been extensively used as a conducting polymer as it exhibits outstanding electrochemical stability while cycling, superior air and thermal stability and good electrical properties as a porous structure which ensures a large electrochemical activity and consistent reversible doping-dedoping process, when the film was tested upon repetitive potential cycling in an electrolyte. The deposition of PEDOT [21] in an ionic liquid medium has been described in the literature, in this case 1-ethyl-3methylimidazolium bis(perfluoroethylsulfonyl)imide (EMIM PFSI). During polymerization in the ionic liquid, both the cation (imidazolium) and the anion (PFSI ${ }^{-}$) of the RTIL are included. PEDOT was also successfully deposited using a $\mathrm{Ag} / \mathrm{AgCl}$ as pseudo-reference electrode (at constant potential of $+0.8 \mathrm{~V}$ for 5 minutes) on $\mathrm{SnO}_{2} / \mathrm{F}$ coated glass from an extremely hydrophobic ionic liquid without any additional dopant [21]. This difference regarding polymer doping illustrates that the ionic liquid can act as both the growth medium and the dopant to produce the polymer film.

PPy colours can change from dark blue (oxidized form) to yellow-green (reduced form), while PEDOT can be switched from light blue (oxidized state) to dark blue (reduced state). PEDOT is a very desirable material for electrochromic devices, especially because of its low band-gap which allows the polymer to be almost transparent (very light blue) in the oxidized state [22]. The simple change from light blue to dark blue limits its application to some degree [23] (e.g. it is not suitable for multicolour applications).

The choice of ionic liquid involves a series of other considerations such as stability, size and nature of ionic liquid ions, the monomer solubility and the viscosity, which can influence the electropolymerization process. When electrochemical deposition of conducting polymers is performed from ionic liquids, the high viscosity at room temperature of some ionic liquids (e.g. 1-hexyl-3-methylimidazolium chloride) may inhibit formation of electroactive polymers at the electrode surface. A very high viscosity produces a significant decrease in the conductivity and slows down the rate of ion diffusion within the ionic liquid. Due to the increased ionic size (3-5 $\AA$ ) of ionic liquids when compared to aqueous electrolytes $(1-2 \AA)$, conductivity at the electrode/ionic liquid interface could be altered.

Copolymers of Py and EDOT have previously been formed in aqueous micellar solution using a non-ionic surfactant, a mixture of $\alpha$ dodecyl polyoxyethylene (8) ether and $\alpha$ tetradecyl polyoxyethylene (8) ether [24]. In this as in other publications, the concentration of EDOT is greater than that of Py. Copolymers were formed in nonaqueous solutions (acetonitrile and propylene carbonate) where the optimum Py:EDOT ratio was 1:5 [25]. Finally PPy-co-PEDOT copolymers were formed in propylene carbonate with a high mole fraction of EDOT (0.925) [26].

To circumvent the relatively high cost of ionic liquids a 'microcell' was used to deposit polymers. Copolymerization of the monomers, Py and EDOT, was performed to obtain one layer, which is expected to have different properties from those of the corresponding homopolymers. Electrochemical copolymerization of PPy with PEDOT was performed in the ionic liquid BMIM $\mathrm{BF}_{4}$ using different monomer ratios. Electrochemical and spectroelectrochemical analysis showed that the properties of the copolymer depend upon the Py/EDOT monomer ratio used.

\section{Experimental}

\subsection{Materials and Equipment}

Pyrrole (Sigma-Aldrich, 98\%) (Py) was stored in dark at $4{ }^{\circ} \mathrm{C}$ and distilled prior to homo-or/co-polymerization. 3,4ethylenedioxythiophene (EDOT) monomer was purchased from Sigma-Aldrich and used without further purification. In order to avoid monomer degradation it was stored in the dark in a refrigerator. The ionic liquid 1-butyl-3-methylimidazolium tetrafluoroborate (BMIM $\left.\mathrm{BF}_{4}\right)$ used for copolymerization was received from Sigma-Aldrich and kept in a dessicator to protect from moisture. Sodium tetrafluoroborate $\left(\mathrm{NaBF}_{4}\right.$, Sigma-Aldrich) was used without any further purification. All aqueous solutions were prepared from deionised water which had a resistivity of $18.2 \mathrm{M} \Omega \mathrm{cm}$ (Elgastat Purification system). The electrochemical results were recorded at room temperature with a $\mathrm{CHI} 600$ electrochemical work station, and all potentials are reported with respect to $\mathrm{Ag} / \mathrm{AgCl}(3 \mathrm{M} \mathrm{KCl})$ reference electrode in aqueous solution. For experiments performed in ionic liquids as electrolytic media, a $\mathrm{Ag}$ wire was used as a pseudo-reference electrode. The monomer solutions ( $20 \mu$ l total volume) prepared for electrochemical deposition of the three copolymers contained the following monomers concentrations: $1: 2$ ratio ( $0.1 \mathrm{M}$ Py: $0.2 \mathrm{M}$ EDOT), $1: 1$ ratio $(0.1 \mathrm{M}$ Py: $0.1 \mathrm{M}$ EDOT) and 2:1 ratio (0.2 M Py: 0.1 M EDOT). For electrodeposition a potential range of $-0.7 \mathrm{~V}$ and $+0.8 \mathrm{~V}$ (vs $\mathrm{Ag}$ wire) and $50 \mathrm{mV} \mathrm{s}^{-1}$ was used. UV-Vis absorption spectra were recorded on a Shzimadzu 1800 UV-Vis spectrophotometer. Spectroelectrochemical studies of the copolymer films was carried out in aqueous solution $\left(0.2 \mathrm{M} \mathrm{NaBF}_{4}\right)$ during successive switching between oxidized to reduced forms. A series of UV spectra were obtained at different potentials. Constant potentials were applied until the current fell to zero and the steady state spectrum was collected. Film morphology was analysed on a Hitachi SU-70 scanning electron microscope (SEM). All experiments described in this article were carried out at room temperature (approximately $18^{\circ} \mathrm{C}$ ). FTIR spectra were collected on a Perkin Elmer Spectrum 100 FTIR with an ATR accessory. 


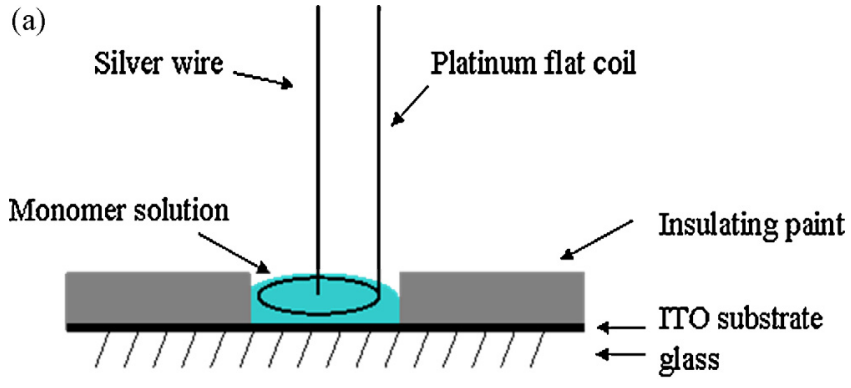

(b)

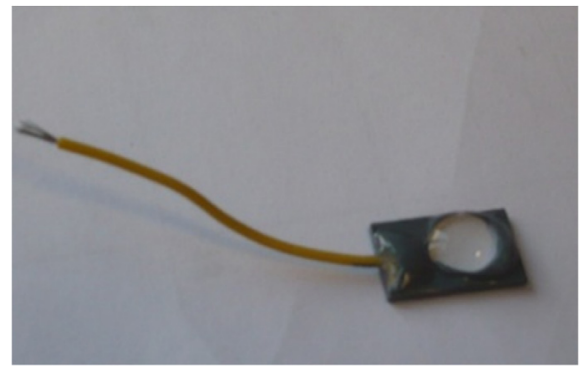

Fig. 1. (a) Schematic diagram showing the cross-section for the microcell arrangement.(b) A photograph of the resulting electrode. This electrode fits into a conventional $1 \mathrm{~cm} \times 1 \mathrm{~cm}$ wide cuvette.

\subsection{Microcell Set-up and Electrode Preparation}

Cyclic voltammetry experiments were performed using a small volume $(20 \mu \mathrm{l})$ three electrode cell (Fig. 1). Indium tin oxide coated glass (ITO, Solaronix, Switzerland) with a resistivity of $18 \Omega$ /sq was used as the conducting working electrode onto which the electropolymers were deposited. The ITO electrodes were cleaned by successive ultrasonication in deionized water, followed by ethanol and deionized water, prior to electrode connection. Copper wire was placed at one edge of the ITO conductive surface and a small amount $(\sim 6 \mu \mathrm{l})$ of silver paint (Electrolube, UK) was attached to form an electrical connection. The paint was allowed to dry for 30 minutes before insulating the electrical connection with epoxy (Araldite) The electrode was covered with insulating paint to define the electrode area (Dielectric paste, The Gwent Group, UK) leaving a disc shaped electrode. The electrodes were heated in an oven (temperature of $70^{\circ} \mathrm{C}$ ) for 15 minutes to allow the paint to dry. A number of layers of insulating paint were deposited to build up the electrode cell working electrode area. The exposed ITO electrode had a diameter of $0.5 \mathrm{~cm}$. A platinum $(\mathrm{Pt})$ coil was placed on top of the droplet (parallel to the ITO electrode surface) as counter electrode, while a silver ( $\mathrm{Ag}$ ) wire was used as pseudo-reference electrode (Fig. 1).

\section{Results and Discussion}

Copolymerization of PPy-co-PEDOT in 1-butyl-3-methylimidazolium tetrafluoroborate

Electrochemical formation of conducting polymers in room temperature ionic liquids has been the subject of interest both from a fundamental and an application point of view. For copolymerization of PPy with PEDOT, the air stable ionic liquid 1butyl-3-methylimidazolium tetrafluoroborate $\left(\mathrm{BMIM} \mathrm{BF}_{4}\right)$ acts as both a supporting electrolyte as well as a dopant. Both polypyrrole and poly(3,4-ethylenedioxythiophene) are well-known polymer materials and have been intensively studied because of their high conductivity, relatively low oxidation potential, chemical stability, and atmospheric stability at room temperature $[27,28]$.

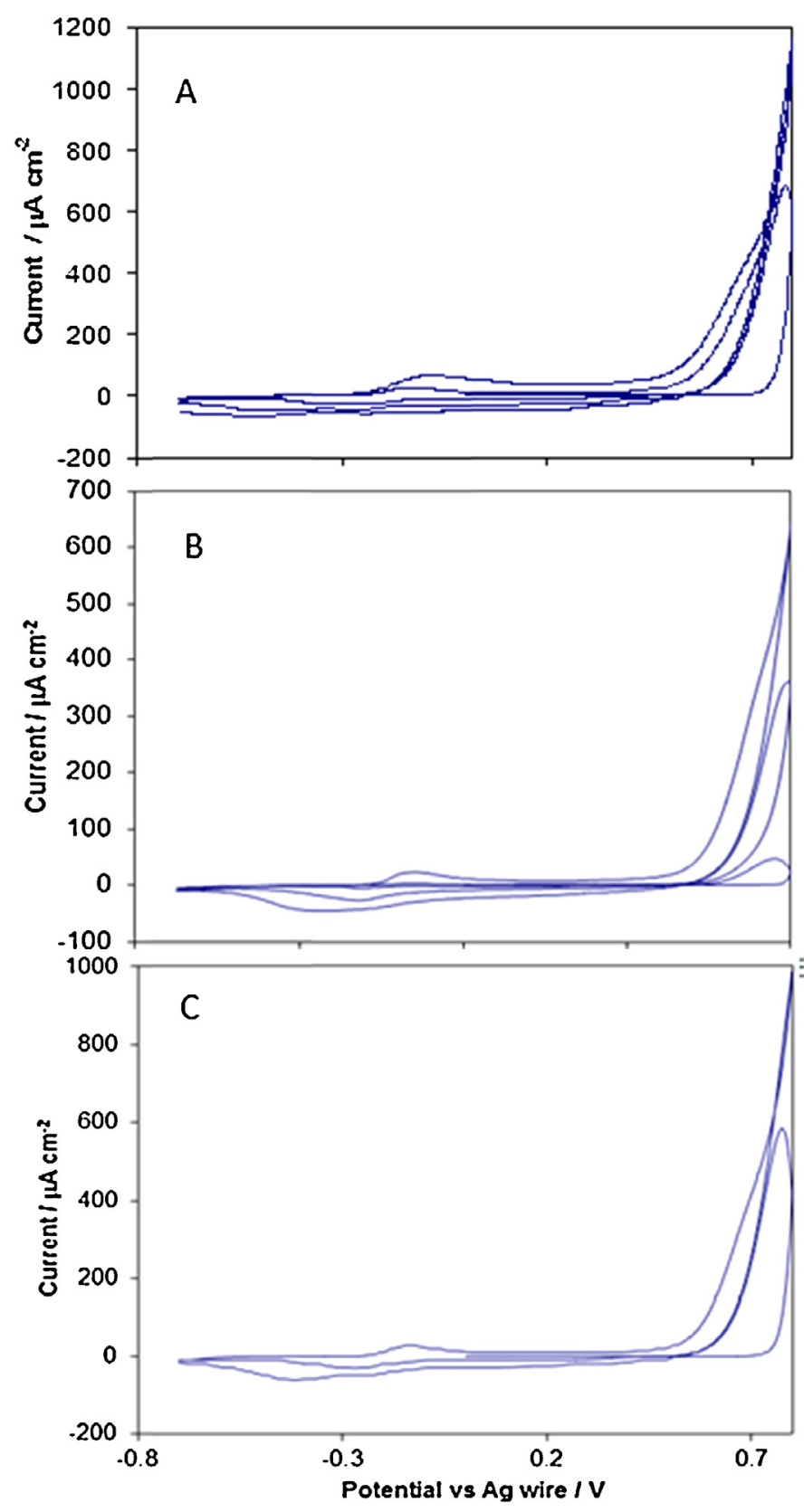

Fig. 2. Cyclic voltammogram for copolymerization of A. PPy-PEDOT (1:2), B. PPyPEDOT (1:1) C. PPy-PEDOT (2:1) in BMIM BF 4 . Scan rate: $40 \mathrm{mV} \mathrm{s}^{-1}$.

Electrochemical deposition of the copolymers was performed in a micro-droplet of ionic liquid (BMIM $\mathrm{BF}_{4}$ ) containing the mixed monomers, pyrrole (Py) and 3,4-ethylenedioxythiophene (EDOT).

The optimal potential range for the formation of copolymers was $-0.7 \mathrm{~V}$ to $0.8 \mathrm{~V}$ versus $\mathrm{Ag}$ wire, which ensured the formation of thin films on the ITO substrate. Potentials higher than $0.8 \mathrm{~V}$ lead to formation of overoxidized films with poor adherence at the electrode surface. The lower limit of $-0.7 \mathrm{~V}$ provided a favourable redox response. Copolymerization of pyrrole with 3,4ethylenedioxythiophene at a molar ratio of $1: 2(0.1 \mathrm{M}$ Py: $0.2 \mathrm{M}$ EDOT), 1:1 (0.1 M Py: 0.1 M EDOT) and 2:1 (0.2 M Py: 0.1 M EDOT) can be seen in Fig. 2 A, B and C, respectively. Film formation started with nucleation on the first oxidation step with successive increases in current density on continuous sweeping leading to the formation of a thin polymeric film on the ITO substrate. 


\subsection{Electrochemical Characterization of PPy-Co-PEDOT}

All three polymer modified ITO electrodes were first examined in monomer-free ionic liquid $\mathrm{BMIM} \mathrm{BF}_{4}$. After film formation, the solution containing the two monomers was removed from the film surface and a fresh drop of ionic liquid applied. The influence of the electrolyte upon the redox behaviour is seen during potential scanning of the copolymers prepared from different molar ratios in both ionic liquid and aqueous solution. During successive cycling in $\mathrm{BMIM} \mathrm{BF}_{4}$, the oxidation and reduction peak potentials were shifted toward more negative values upon decreasing the EDOT concentration in the monomers solution. Also the currents continued to decrease in neat BMIM $\mathrm{BF}_{4}$ with decreasing amounts of EDOT.

During potential cycling in pure BMIM $\mathrm{BF}_{4}$, cyclic voltammograms of the PPy-co-PEDOT (1:2) film (Fig. 3 A) showed increases in the peak currents with increased scan rates. A linear relationship between both the anodic and cathodic peaks versus scan rate was observed, indicative of thin layer behaviour [29]. The oxidation peak potential, $\mathrm{E}_{\mathrm{p}}{ }^{\mathrm{f}}$ situated at $-0.04 \mathrm{~V}$ became more prominent as the scan rate was increased, while the reduction peak was very broad and shifted towards more positive potentials. The electrochemical study of the film was continued in aqueous solution that contained anions of the same size, in this case $\mathrm{BF}_{4}{ }^{-}$. During continuous potential scanning in an aqueous solution of $0.2 \mathrm{M}$ $\mathrm{NaBF}_{4}$ (Fig. 3.D), both the oxidation and reduction peaks appeared broader and smaller, which suggests that the rate of ion-exchange decreased in this medium.

Due to modifications of electrolytic media, significant differences appear when PPy-co-PEDOT was cycled in aqueous solution at the same potential range of $-0.5 \mathrm{~V}$ to $0.5 \mathrm{~V}$ ( $\mathrm{vs}$. $\mathrm{Ag} / \mathrm{AgCl}, 3 \mathrm{M} \mathrm{KCl}$ ). Both anodic and cathodic peak potentials were located in the potential range of $-0.2 \mathrm{~V}$ and $0 \mathrm{~V}$, while in aqueous solution at high scan rates of 100 or $150 \mathrm{mV} \mathrm{s}^{-1}$ the peak potentials shifted to more positive values of around $0.0 \mathrm{~V}$. When the PPy-co-PEDOT (1:2) was transferred to aqueous solution, the peak currents disappeared and the voltammetry appeared more capacitive at $100 \mathrm{mV} \mathrm{s}^{-1}$. This could be explained by the effects of double layer charging as seen in Fig. 3 D.

The electrochemical behaviour of PPy-co-PEDOT (1:1) in neat BMIM $\mathrm{BF}_{4}$ is presented in Fig. 3.B where both the anodic and cathodic peaks became more pronounced with increased scan rate. This means that the reduction and oxidation of the copolymer was characterized by faster kinetics (greater ion mobility) which may arise from decreased amounts of EDOT. In addition the oxidation peak current appeared at the same potential position $(-0.1 \mathrm{~V})$, while the reduction peak was slightly moved in a negative direction to $-0.2 \mathrm{~V}$. The same film of PPy-co-PEDOT (1:1) was subsequently scanned in $0.2 \mathrm{M} \mathrm{NaBF}_{4}$ aqueous solution (Fig. 3.E). In aqueous solution the copolymer presents a significant increase of the capacitive current component and the occurrence of broad potential peaks as was also the case with the PPy-co-PEDOT (1:2) film.

The maximum currents of $120 \mu \mathrm{Acm}^{-2}$ at $150 \mathrm{mV} \mathrm{s}^{-1}$ in BMIM $\mathrm{BF}_{4}$ (Fig. 3.B) are higher compared to the ones when the films were scanned in $0.2 \mathrm{M} \mathrm{NaBF}_{4}$ (Fig. 3.E), indicating that the films have lost from their electroactivity. A decrease of $\Delta \mathrm{E}_{\mathrm{p}}$ value for PPy-co-PEDOT $(1: 1)$ copolymer in aqueous solution $\left(\Delta \mathrm{E}_{\mathrm{p}}=63 \mathrm{mV}\right)$ occurred, compared to $\Delta E_{p}$ of $88 \mathrm{mV}$ obtained for the voltammograms in pure BMIM $\mathrm{BF}_{4}$.

For the copolymer film PPy-co-PEDOT (2:1) (Fig. 3.C) electrochemical characterization was performed in a similar manner to PPy-co-PEDOT (1:2) and PPy-co-PEDOT (1:1). The electrochemical response of PPy-co-PEDOT (2:1) showed a clear increase in peak currents with increased scan rate (Fig. 3.C). The film exhibited fast kinetics which is evident from the sharp peak potential at $-0.15 \mathrm{~V}$ sharp film voltammetry in the 1-butyl-3methylimidazolium tetrafluoroborate ionic liquid on successive
Table 1

Table of forward peak potential $\left(E_{p}{ }^{f}\right)$ and peaks separation $\left(\Delta E_{p}\right)$ of copolymer for different PPy/PEDOT ratios.

\begin{tabular}{llll}
\hline PPy ratio & PEDOT ratio & $\mathrm{E}_{\mathrm{p}}{ }^{\mathrm{f}}$ & $\Delta \mathrm{E}_{\mathrm{p}}$ \\
\hline 1 & 2 & $>-0.04 \mathrm{~V}$ & $93 \mathrm{mV}$ \\
1 & 1 & $-0.1 \mathrm{~V}$ & $88 \mathrm{mV}$ \\
2 & 1 & $-0.15 \mathrm{~V}$ & $113 \mathrm{mV}$ \\
1 & 0 & varies & - \\
0 & 1 & $0.1 \mathrm{~V}$ & $\sim 100 \mathrm{mV}$ \\
\hline
\end{tabular}

potential cycling. As expected, when the film was placed in aqueous solution (Fig. 3.F), on continuous potential scanning the PPyco-PEDOT (2:1) copolymer displayed broad oxidation/reduction potential peaks. The resulting copolymer PPy-co-PEDOT thickness, $\mathrm{L}$, had a value of $15 \mathrm{~nm}\left(\mathrm{Q}=6.3 \times 10^{-4} \mathrm{Ccm}^{-2}\right)$, obtained from the following relationship:

$\mathrm{L}=\mathrm{QW} /(2.25 \mathrm{~F} \sigma \mathrm{A})$

where $\mathrm{Q}\left(\mathrm{Ccm}^{-2}\right)$ is the charge passed during growth, $\mathrm{W}\left(\mathrm{g} \mathrm{mol}^{-1}\right)$ is the molecular weight of the monomer, $\mathrm{F}\left(96485 \mathrm{C} \mathrm{mol}^{-1}\right)$ is Faraday's constant, $\sigma\left(\mathrm{g} \mathrm{cm}^{-3}\right)$ the density of monomer and 2.25 is the number of electrons transferred. It was assumed that no swelling, due to the presence of electrolyte, occurred [30].

The scan rate dependence of the anodic and cathodic peak currents was linear for the voltammograms in Fig. 3. This demonstrates that the electrochemical process is representative of thin layer behaviour. However the $\Delta \mathrm{E}_{\mathrm{p}}$ for all copolymers was greater than $0 \mathrm{mV}$ as presented in Table 1 . Actually all copolymers were electrochemically active and their characteristics being dependent upon the monomer concentration ratios involved.

FTIR spectra of each of the PPy-co-PEDOT films, 2:1, $1: 1$ and $2: 1$ had peaks at $1052 \mathrm{~cm}^{-1}(\mathrm{C}-\mathrm{O}-\mathrm{C}$ stretching) and $820 \mathrm{~cm}^{-1}$ (C-S stretching) indicative of PEDOT along with bands at $1557 \mathrm{~cm}^{-1}$ (stretching mode of $\mathrm{C}=\mathrm{C}$ ) and $1170 \mathrm{~cm}^{-1}$ (C-N stretching) indicative of Py. That these FTIR peaks are present in the films demonstrates copolymer formation as described elsewhere $[24,25]$.

\subsection{In-situ Spectroelectrochemistry of PPy-co-PEDOT Copolymers}

A spectroelectrochemical study of the copolymers was performed in order to obtain evidence for electrochemical copolymerization and to elucidate the electronic transitions upon oxidation/reduction of the copolymers. To do this, the fresh copolymers were transferred into cuvettes containing monomer free aqueous electrolyte $0.2 \mathrm{M} \mathrm{NaBF}_{4}$.

In situ spectroelectrochemistry of PEDOT formed in BMIMBF 4 and transferred to aqueous $0.2 \mathrm{M} \mathrm{NaBF}_{4}$ yielded only a slight change in the spectrum as a function of applied potential. This is an indication of the slow ion movement as has been described when PEDOT was formed previously in an ionic liquid: 1-butyl methylpyrrolidinium bis(trifluoromethane sulphonyl) imide [31]. The formation of a Py and EDOT copolymer aims to improve the ion mobility.

Fig. 4 A shows the absorbance change over the potential range $0.8 \mathrm{~V}$ (oxidation potential) to $-0.6 \mathrm{~V}$ (reduction potential) for the PPy-co-PEDOT (1:2) electrode. The film showed very little change in absorbance over the visible range. Upon reduction of the film, a broad absorbance peak was seen at $400 \mathrm{~nm}$, which increased with decreasing potential values and a polaron peak was observed at $507 \mathrm{~nm}$.

The potential-dependent change in the peak intensities of the absorbance upon p-doping for PPy-co-PEDOT (1:1) film in $0.2 \mathrm{M}$ $\mathrm{NaBF}_{4}$ aqueous solution is illustrated in Fig. 4.B. Similar to PPyCo-PEDOT (1:2), the PPy-co-PEDOT (1:1) films showed very little change in absorbance over the UV-Vis range and a clear isosbestic 

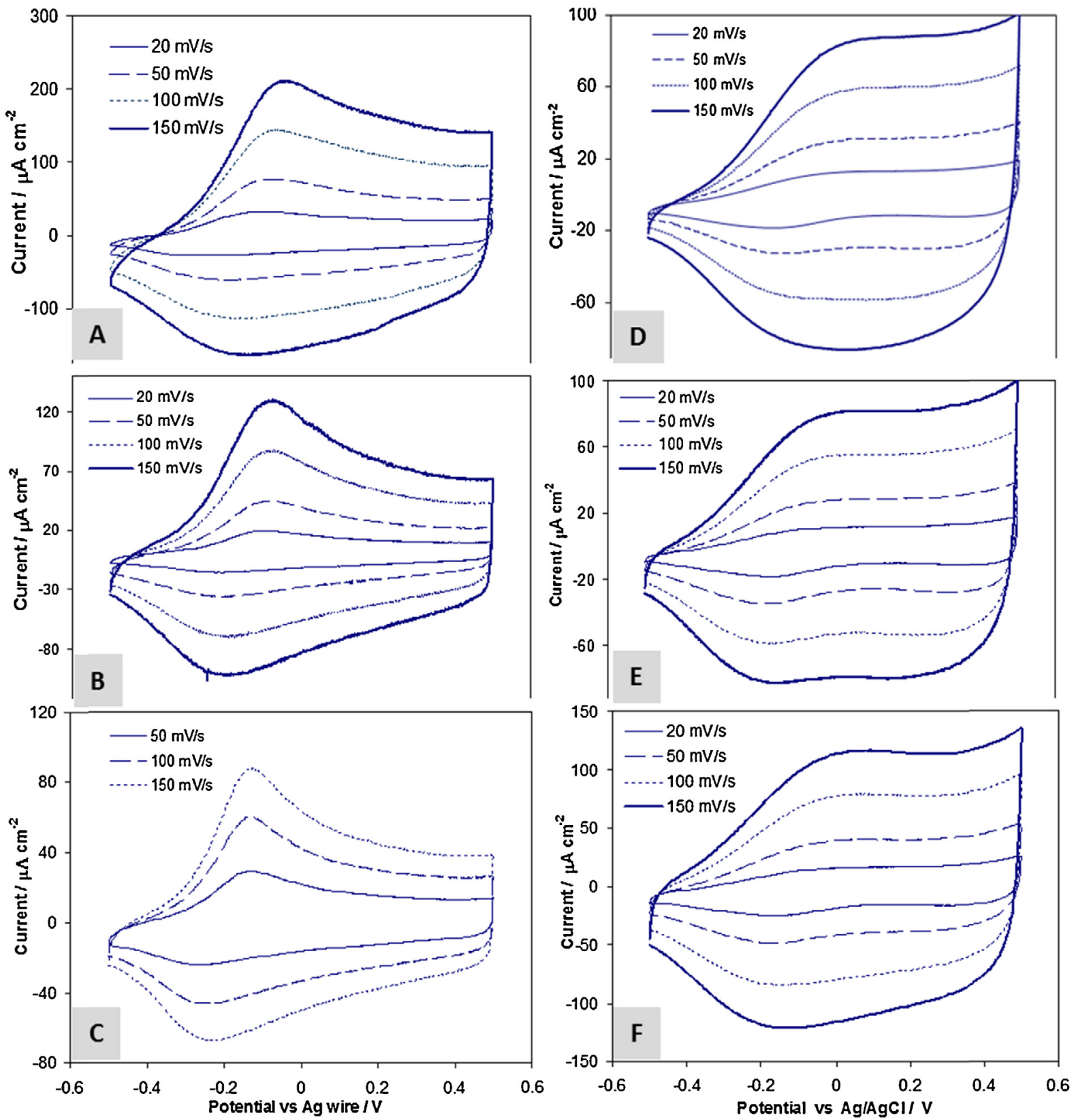

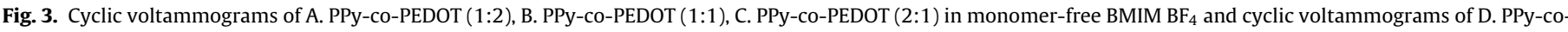
PEDOT (1:2), E. PPy-Co-PEDOT(1:1), F. PPy-co-PEDOT (2:1) in in monomer-free aqueous. solution $0.2 \mathrm{M} \mathrm{NaBF}_{4}$.

point was not observed. Upon successive reduction of PPy-coPEDOT (1:1) thin film in an aqueous solution of $0.2 \mathrm{M} \mathrm{NaBF}_{4}$, the $\pi-\pi^{*}$ transition intensity was reduced and the formation of charge carrier bands was observed. The appearance of the broad absorbance peak at $540 \mathrm{~nm}$ can be attributed to the presence of a polaron band (Fig. 4.B).

In Fig. 4.C the reduction process of 'polypyrrole dominated' copolymer PPy-co-PEDOT (2:1) in aqueous solution $0.2 \mathrm{M} \mathrm{NaBF}_{4}$, showed a sharp absorbance peak at $380 \mathrm{~nm}$ in the reduced form. $\lambda_{\max }$ occurred close to $400 \mathrm{~nm}$ and also significant changes in the absorbance were noticed compared to PPy-co-PEDOT (1:2) and PPy-Co-PEDOT (1:1). At $580 \mathrm{~nm}$ a broad shoulder appeared due to polaron formation [32].

Comparing the spectroelectrochemical results of PEDOT and copolymers, the $\lambda_{\max }$ for neutral PEDOT was $520 \mathrm{~nm}$. In Fig. 4.A, B, C no isosbestic point is present and each of the spectra show the presence of neutral, polaron and bipolaron peaks. The absorbance peak in the neutral form is at the same wavelength for all the copolymers and is dominated by pyrrole. The bipolaron peak was broad in each case and the maximum wavelength was difficult to determine.

The evolution of a polaron peak appears to be directly related to the change of Py: EDOT monomer ratio (Table 2). In all three copolymers the polaron state is stable, unlike the PEDOT polymer where the equilibrium lies to the right hand side presented in equation (2):

2polarons $\rightleftharpoons$ neutral + bipolaron

Table 2

$\lambda_{\max }$ of polaron peak as a function of the ratios of PPy/PEDOT.

\begin{tabular}{llll}
\hline PPy & PEDOT & $\lambda_{\max }(\mathrm{nm})$ & Fig. 3 \\
\hline 1 & 2 & 507 & $\mathrm{~A}$ \\
1 & 1 & 540 & $\mathrm{~B}$ \\
2 & 1 & 580 & $\mathrm{C}$ \\
\hline
\end{tabular}



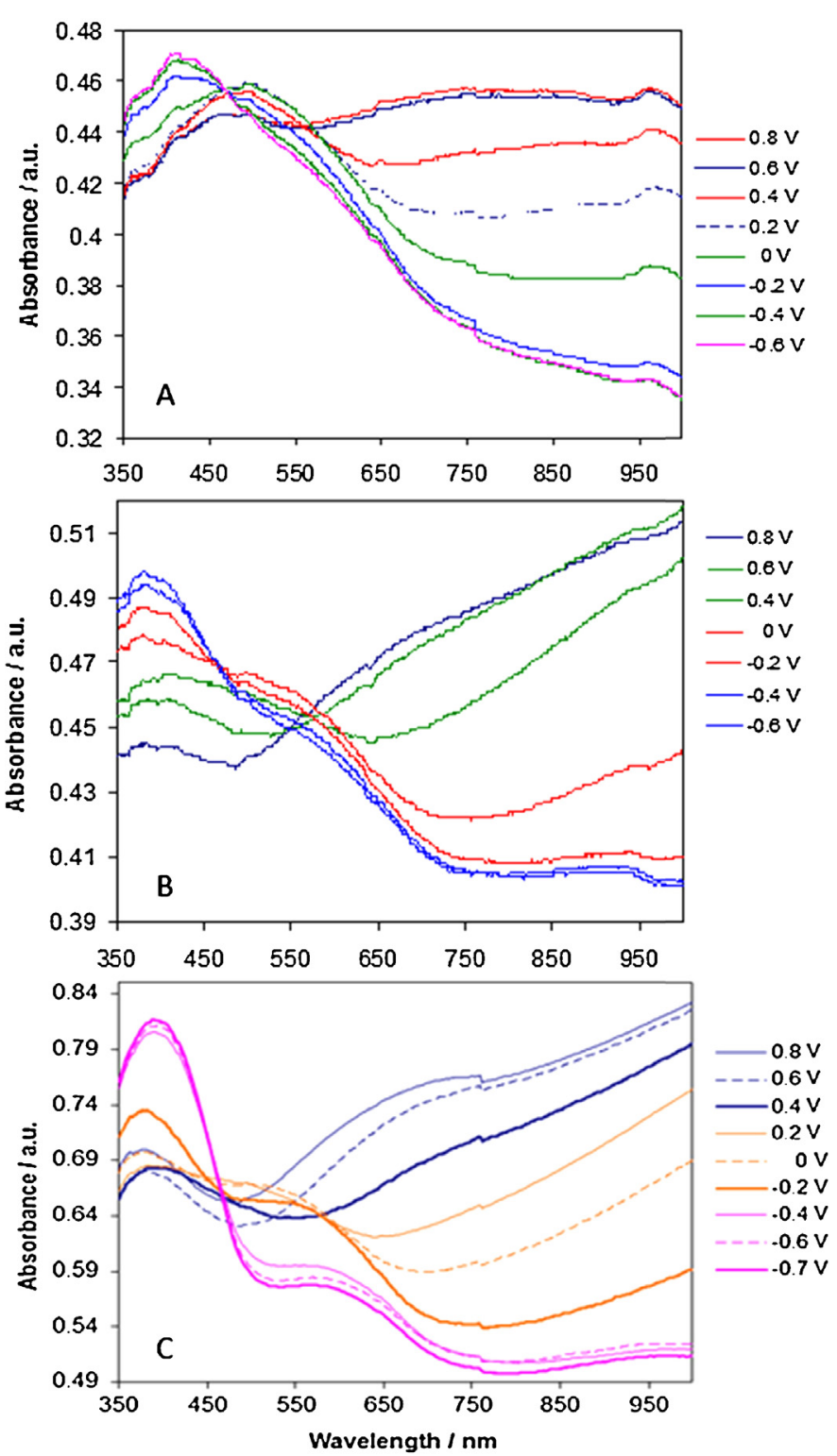

Fig. 4. UV-Vis spectroelectrochemical spectra of A. PPy-co-PEDOT (1:2), B. PPy-coPEDOT (1:1) and C. PPy-Co-PEDOT (2:1) films on ITO as function of applied potentials from $0.8 \mathrm{~V}$ down to $-0.6 \mathrm{~V}$ in $0.2 \mathrm{M} \mathrm{NaBF}_{4}$ aqueous solution.

Thus it is clear that the polaron band gap can be modulated by changing the Py: EDOT monomer ratio. Even when a small amount of pyrrole is present such as in Py-co-PEDOT of 1:2 (Fig. 4.A), the polaron is stabilised. That there is a greater proportion of Py in the copolymer can be seen from the position of the $\lambda$ max of the neutral $\pi \rightarrow \pi^{*}$ transition which in this work is at $392 \mathrm{~nm}$ for the $1: 1$ and 2:1 Py: EDOT films, while it occurs at $417 \mathrm{~nm}$ for the 1:2 Py: EDOT copolymer. This is unlike the position of the neutral band at $508 \mathrm{~nm}$ for a 1:5 Py:EDOT ratio[25] and $542 \mathrm{~nm}$ for a py: EDOT ratio of 1:10 formed from the micellar solution [24]

In Fig. 5 it can be seen that the absorbance increases well beyond the peak current compared to the voltammetric response at slow scan rate obtained in the same conditions. This indicates that the region past the peak associated with double layer charging also comprises a faradaic current component. Similar results were reported by Hutton, Kalaji and Peter [33], who reported that the current at higher potentials is not solely due to double layer charging. Their study was done using an $80 \mathrm{~nm}$ polyaniline film deposited on ITO glass at $20 \mathrm{mV} \mathrm{s}^{-1}$. The absorption of polyaniline at $620 \mathrm{~nm}$

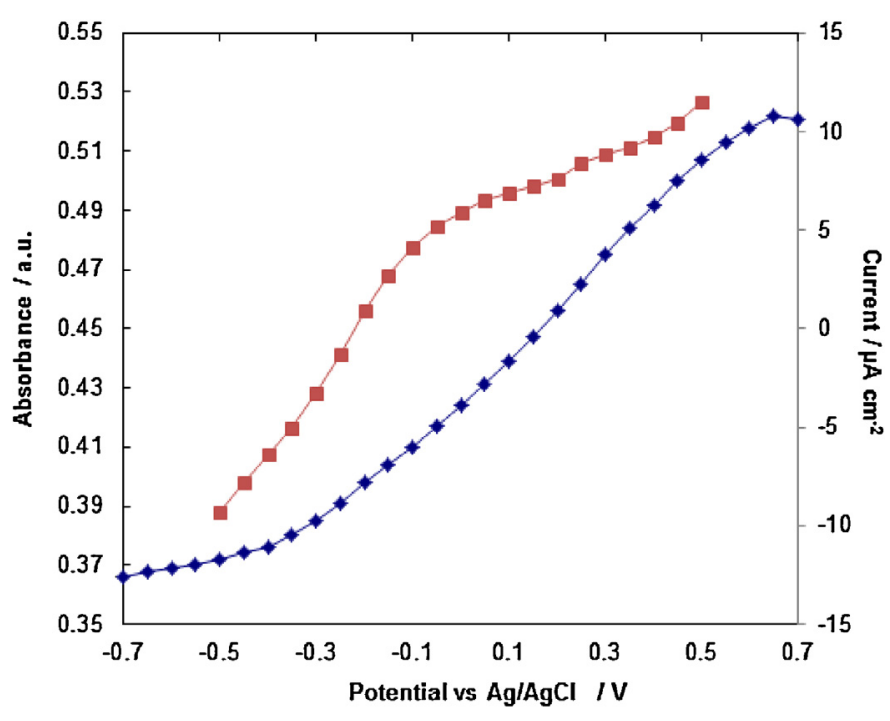

Fig. 5. Absorbance evolution with time at $700 \mathrm{~nm}$ (bottom line) and oxidation cycle (top line) at $10 \mathrm{mV} / \mathrm{s}$ scan rate of the PPy-co-PEDOT (2:1) copolymer in $0.2 \mathrm{M} \mathrm{NaBF}_{4}$ aqueous solution. Potential range $-0.7 \mathrm{~V}$ to $0.7 \mathrm{~V}$.

as a function of potential since polyaniline presents a maximum absorbance at this wavelength upon oxidation. The results showed a continuous increase in absorbance during oxidation, observed beyond the peak in the voltammogram [33]. This was associated with rapid charge transfer which meant that there was a faradaic pseudo-capacitive component. The non-linearity seen in the plot of absorbance versus potential (Fig. 5) indicated that more than one absorbing species was formed (e.g. polaron and bipolaron species [34]).

\subsection{Electrochromic Switching Studies}

The spectral variation corresponds to a change of colour from oxidized form (grey-blue) to a reduced form (olive-green). The ability of the polymer to change its colour in a reversible manner is of central importance for display applications [22,35]. The PPyco-PEDOT copolymer exhibited systematic changes in the visible absorbance spectrum and this was seen as a promising material for electrochromic applications. The physical stability of the layer was preserved since the potential was maintained between $-0.7 \mathrm{~V}$ and $+0.8 \mathrm{~V}$ to prevent overoxidation. It was found [36] that overoxidation of a polypyrrole layer caused repulsion of the film. PEDOT has been shown to be resistant against overoxidation in propylene carbonate, even with small levels of PPy (less than 0.15 mole fraction) present in a copolymer [26]. A copolymer of Py:EDOT at a ratio of $1: 10$ retained $80 \%$ of its electroactivity after 1000 cycles up to $+0.7 \mathrm{~V}$ [24]. In addition a sandwich electrochromic device consisting of chemically synthesised PEDOT and PPy layers separated by a polyelectrolyte gel was found to lose only $8 \%$ of its phototropic $\% \Delta \mathrm{T}$ response at $560 \mathrm{~nm}$ after 10,000 cycles where $\pm 1.5 \mathrm{~V}$ was applied [37]. This supports the assertion that PPy and PEDOT possess electrochemical stability, once the applied potentials are not too great. The PPy-co-PEDOT (2:1)/BMIM $\mathrm{BF}_{4}$ system was studied in detail in order to explore its properties as an electrochromic material. The copolymer formed from the ionic liquid was used in aqueous solution when spectroelectrochemical experiments were carried out.

The PPy-co-PEDOT (2:1) electrochromic response was performed at wavelengths of $400 \mathrm{~nm}$, applying a potential between $-0.7 \mathrm{~V}$ and $0 \mathrm{~V}$ (Fig. 6). The film exhibited reversible behaviour and a relatively fast switching time of 20 seconds [38]. An important characteristic of electrochromic films is the coloration efficiency $\eta$ 


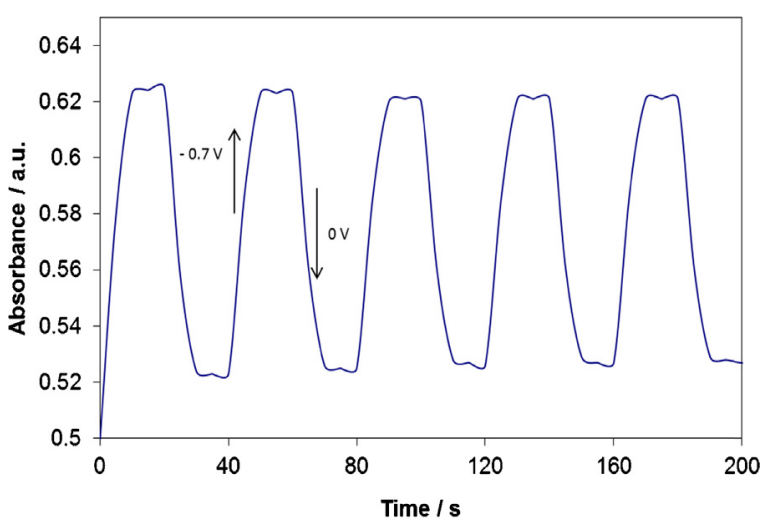

Fig. 6. Electrochromic switching response for PPy-co-PEDOT (2:1) monitored at $400 \mathrm{~nm}$. Potentials applied at $20 \mathrm{~s}$ intervals. Potential limits: $-0.7 \mathrm{~V}$ to $0 \mathrm{~V}$.

(CE), which is calculated using the following equation derived from Beer-Lambert law [39]:

$C E=\frac{\Delta A}{Q_{d}}=\frac{\log \frac{T_{o x}}{T_{\text {neut }}}}{Q_{d}}$

where $Q_{d}$ is the charge in $C \mathrm{~cm}^{-2}, C E(\eta)$ is in $C^{-1} \mathrm{~cm}^{2}$, and $T_{o x}$ and $\mathrm{T}_{\text {neut }}$ are the transmittance value of oxidized and reduced state. For the present study the value for $\Delta \mathrm{A}$ was used, as shown in Fig. 6.

Colouration efficiency CE $(\eta)$ is related to the performance of the electrochromic device and is defined as the ratio between the change in optical density $(\Delta \mathrm{OD})$ and the injected/ejected charge per unit area of the electrode at a specific wavelength $\left(\lambda_{\max }\right)$ [40]. For $\lambda_{\max }=400 \mathrm{~nm}$, the PPy-co-PEDOT (2:1) copolymer had a colouration efficiency of $101.3 \mathrm{C}^{-1} \mathrm{~cm}^{2}$, which is a reasonable value for an electrochromic material [35,41]. CE values between 74 and 147 $\mathrm{cm}^{2} \mathrm{C}^{-1}$ have previously been obtained for a Py:EDOT copolymer formed from micellar solutions [24].

A change of colours in the copolymeric films could be observed upon their electrochemical oxidation/reduction. The PPyco-PEDOT (2:1) colours were different from those of PPy and PEDOT, as they exhibited olive-green in the oxidized state and bluegrey in the reduced form. The colours seen for the PPy-co-PEDOT (1:2) had a green-yellow appearance in the reduced form and a blue-green colour in the oxidized state. The copolymer having equal monomer ratios (PPy-co-PEDOT, 1:1) exhibited a yellow-green colour in the reduced form and a (darker) grey-blue colour in the oxidized state.

\subsection{Morphological Features}

Polymer films of PPy, PEDOT, PPy-co-PEDOT (1:2), PPy-coPEDOT (1:1), PPy-Co-PEDOT (2:1) characterized by scanning electron microscopy (SEM). The films were rinsed with acetonitrile in order to remove traces of ionic liquid and dried in air before the analysis. All three copolymer films prepared from different monomer ratios and observed on the SEM exhibited distinctly different morphologies.

The morphologies of new copolymers displayed different features compared to PPy/BMIM $\mathrm{BF}_{4}$ and PEDOT/BMIM BF 4 . PEDOT homopolymers are known to be porous films [42], while PPy films are characterized by a cauliflower-like appearance [43]. The PPyco-PEDOT (1:2) (Fig. 7.A) film had a distribution of globules, pores and holes which indicated the incorporation of both PPy and PEDOT to produce the new copolymer. It is interesting to observe that the PPy-co-PEDOT (1:1) (Fig. 7.B) film displayed a featureless structure.

In contrast the appearance of the PPy-Co-PEDOT (1:1) was very different, since this copolymer shows an array of very small granules. The PPy-co-PEDOT (1:1) morphology is strikingly different

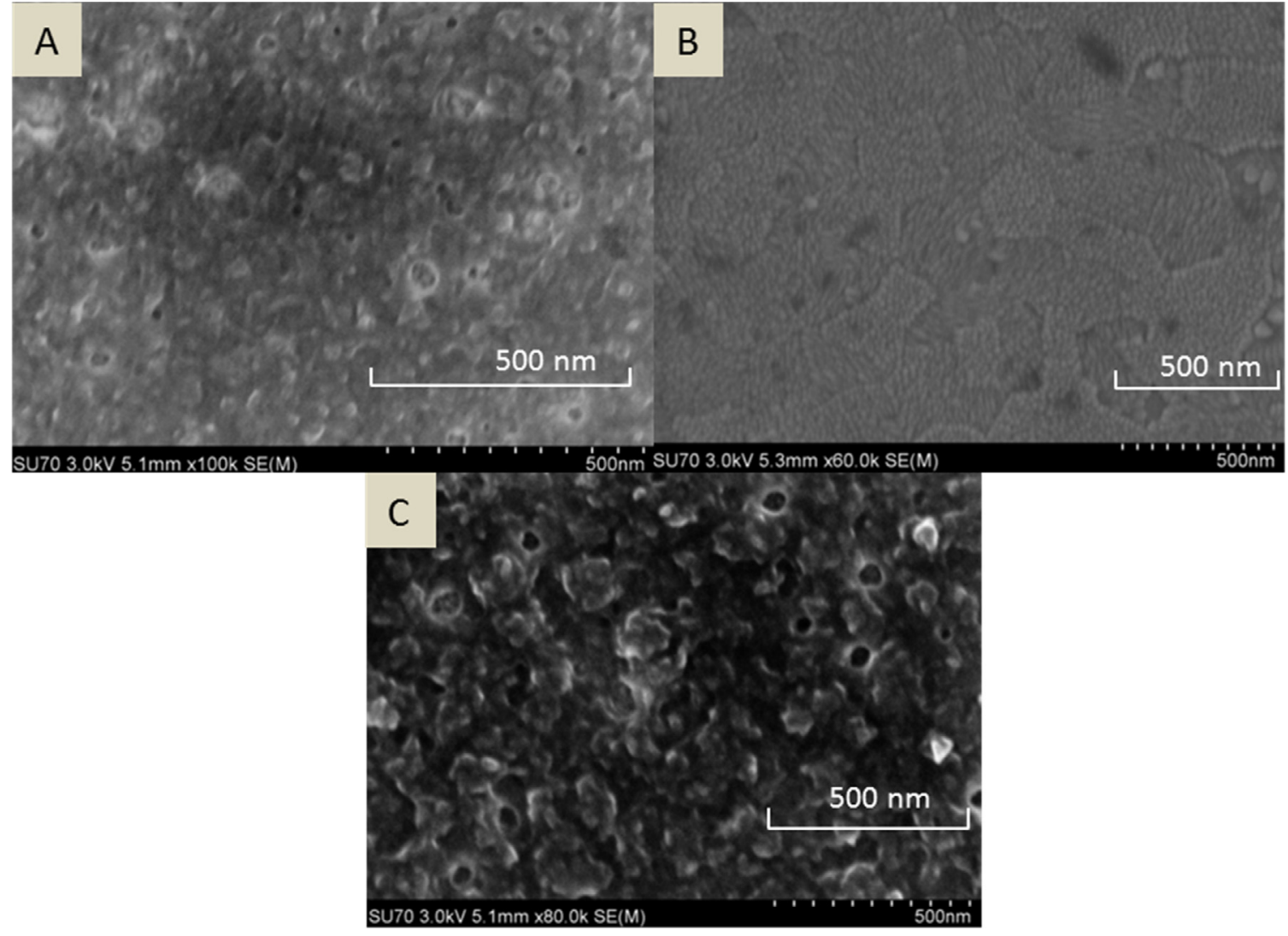

Fig. 7. SEM images of A. PPy-PEDOT (1:2), B. PPy-PEDOT (1:1) and C. PPy-PEDOT (2:1) films. 
from the 'polypyrrole dominated' copolymer PPy-co-PEDOT (2:1) (Fig. 7.C), which presents bigger clusters of globules and holes with increased diameter. The SEM analysis of PPy-co-PEDOT (2:1) was interesting to observe since this polymer displayed the best electrochomic properties. The appearance of pores with increased diameter could account for the good electrochemical behaviour, from the perspective of ions which can be injected/ejected easily into/out of the polymer matrix. The rougher surface of the PPy-CoPEDOT (2:1) film may explain the improved response, when cycled

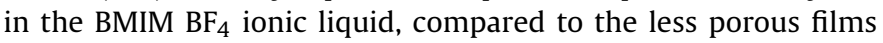
PPy-co-PEDOT (1:2) and PPy-co-PEDOT (1:1) respectively.

The electron micrographs of each copolymer revealed different surface morphology depending on the monomers concentration ratios. The difference in the film morphologies is consistent with the significant differences in the electrochemical properties of the three copolymers.

\section{Conclusions}

For the present study, new PPy-co-PEDOT copolymers were successfully synthesised by electrochemical oxidation of monomer mixtures in BMIM $\mathrm{BF}_{4}$ ionic liquid using a novel microcell setup. The copolymers prepared in three different ratios were further characterized by several means such as cyclic voltammetry, insitu UV-Vis spectroelectrochemistry, scanning electron microscopy and spectrochronoamperometry. According to the cyclic voltammograms (CVs) of the copolymer film obtained in both BMIM $\mathrm{BF}_{4}$ and aqueous electrolyte, different electrochemical responses were observed when the copolymers were removed from their growth medium. The CVs of the copolymers curves showed welldefined redox processes comparable to earlier studies done by Tao et al. [24,25]. The current density was directly proportional to the scan rate indicating the presence of an electroactive thin film.

The in-situ spectroscopic measurement performed as a function of potential confirmed PPy-co-PEDOT (2:1) as the best behaved copolymer, as only for this copolymer were transitions from neutral to polaron and bipolaron seen. These results are comparable to the UV-Vis spectra upon oxidation of PPy-co-PEDOT copolymers in acetonitrile [40]. The copolymers study was completed by SEM analysis, which highlighted the differences in morphology of the copolymers to that of the homopolymers. In comparison for PPy-co-PEDOT films formed in acetonitrile [24,25], the SEM images revealed various accumulations of globules and a porous appearance, according to the amount of pyrrole present in the sample. Previously copolymers with a high proportion of EDOT have been described, whose spectroelectrochemical behaviour was dominated by EDOT (where equation 2 lay to the right hand side). In this work the polaron stabilising effect of including Py in the copolymer is shown. In addition there is a greater ion mobility for the copolymer compared to PEDOT.

Different colours were observed for the oxidized and reduced forms of the copolymers formed in the three monomer ratios. The PPy-co-PEDOT (2:1) colours were different from those of PPy and PEDOT, as they changed from olive-green to blue-grey when switching between oxidized and reduced form. The colours seen for the PPy-Co-PEDOT (1:2) had a yellow-green appearance in the reduced state and a blue-green colour in the oxidized state. The copolymer prepared in equal monomer ratios (PPy-Co-PEDOT, 1:1) exhibited a yellow-green colour in the reduced form and a (darker) grey-blue colour in the oxidized state.

\section{Acknowledgement}

This work was financially supported by the University of Limerick and Dublin Institute of Technology Joint Common
Interest Group scheme, Ireland and the Programme for Third Level Institutions (cycle IV) funded nanoscience programme, INSPIRE.

\section{Appendix A. Supplementary data}

Supplementary material related to this article can be found, in the online version, at http://dx.doi.org/10.1016/j.electacta. 2013.10.198.

\section{References}

[1] T.A. Skotheim, R.L. Elsenbaumer, J.R. Reynolds, Handbook of Conducting Polymers, Marcel Dekker, New York, 1998.

[2] E. Frackowiak, V. Khomenko, K. Jurewicz, K. Lota, F. Beguin, Supercapacitors based on conducting polymers/nanotubes composites, Journal of Power Sources 153 (2006) 413-418

[3] S. Aytaç, F. Kuralay, I.H. Boyacı, C. Unaleroglu, A novel polypyrrole phenylboronic acid based electrochemical saccharide sensor, Sensors and Actuators B: Chemical 160 (2011) 405-411.

[4] C.J. Brabec, N.S. Sariciftci, J.C. Hummelen, Plastic solar cells, Advanced Functional Materials 11 (2001) 15-26.

[5] A.A. Argun, A. Cirpan, J.R. Reynolds, The first truly all-polymer electrochromic devices, Advanced Materials 15 (2003) 1338-1341.

[6] A. Kraft, A.C. Grimsdale, A.B. Holmes, Electroluminescent conjugated polymers - seeing polymers in a new light, Angewandte Chemie-International Edition 37 (1998) 402-428

[7] C. Plesse, F. Vidal, H. Randriamahazaka, D. Teyssié, C. Chevrot, Synthesis and characterisation of conducting interpenetrating polymer networks for new actuators, Polymer 46 (2005) 7771-7778.

[8] J.M. Pringle, J. Efthimiadis, P.C. Howlett, D.R. MacFarlane, A.B. Chaplin, S.B. Hall, D.L. Officer, G.G. Wallace, M. Forsyth, Electrochemical synthesis of polypyrrole in ionic liquids, Polymer 45 (2004) 1447-1453.

[9] D. Kumar, R.C. Sharma, Advances in Conductive Polymers, European Polymer Journal 34 (1998) 1053-1060.

[10] A.J.C. da Silva, F.A. Ribeiro Nogueira, J. Tonholo, A.S. Ribeiro, Dual type electrochromic device based on polypyrrole and polythiophene derivatives', Solar Energy Materials and Solar Cells 95 (2011) 2255-2259.

[11] J.P. Ferraris, M.M. Eissa, I.D. Brotherston, D.C. Loveday, A.A. Moxey, Preparation and electrochemical evaluation of poly(3-phenylthiophene) derivativespotential materials for electrochemical capacitors, Journal of Electroanalytical Chemistry 459 (1998) 57-69.

[12] K. Crowley, J. Cassidy, In situ resonance Raman spectroelectrochemistry of polypyrrole doped with dodecylbenzenesulphonate, Journal of Electroanalytical Chemistry 547 (2003) 75-82.

[13] M.D. Levi, C. Lopez, E. Vieil, M.A. Vorotyntsev, Influence of ionic size on the mechanism of electrochemical doping of polypyrrole films studied by cyclic voltammetry, Electrochimica Acta 42 (1997) 757-769.

[14] A.P. Abbott, K.J. McKenzie, Application of ionic liquids to the deposition of metals, Physical Chemistry Chemical Physics 8 (2006) 4265-4279.

[15] P. Yu, J. Yan, J. Zhang, L. Mao, Cost effective electrodeposition of platinum nanoparticles with ionic liquid droplet confined onto electrode surface as micromedia, Electrochemistry Communications 9 (2007) 1139-1144.

[16] F. Endres, Ionic Liquids- solvents for the electrodeposition of metals and semiconductors, ChemPhysChem 3 (2002) 144-154.

[17] F. Endres, D. MacFarlane, A. Abbott, Electrodeposition from Ionic Liquids, Wiley, New York, 2008.

[18] D.R. MacFarlane, J.M. Pringle, P.C. Howlett, M. Forsyth, Ionic liquids and reactions at the electrochemical interface Physical Chemistry Chemical Physics 12 (2010) 1659-1669.

[19] J.H. Mazurkiewicz, P.C. Innis, G.G. Wallace, D.R. MacFarlane, M. Forsyth, Conducting polymer electrochemistry in ionic liquids, Synthetic Metals 135 (2003) 31-32.

[20] K. Sekiguchi, M. Atobe, T. Fuchigami, Electropolymerisation of pyrrole in 1ethyl-3-methylimidazolium trifluoromethanesulphonate room temperature ionic liquid, Electrochemistry Communications 4 (2002) 881-885.

[21] S. Ahmad, M. Deepa, S. Singh, Electrochemical synthesis and surface characterization of poly(3,4-ethylenedioxythiophene) films grown in an ionic liquid Langmuir 23 (2007) 11430-11433.

[22] P. Camurlu, L. Toppare, Dual complementary colored polymer electrochromic devices based on conducting polymers of poly(hexanedioic acid bis-(2 thiophen-3-yl ester), Journal of Macromolecular Science-Pure and Applied Chemistry A43 (2006) 449-458.

[23] F. Tran-Van, L. Beouch, F. Vidal, P. Yammine, D. Teyssie, C. Chevrot, Self supporting semi interpenetrating polymer networks for new design of electrochromic devices, Electrochimica Acta 53 (2008) 4336-4343.

[24] Y. Tao, H. Cheng, W. Zheng, Z. Zhang, D. Liu, Electrosynthesis and characterizations of copolymers based on pyrrole and 3,4-ethylenedioxythiophene in aqueous micellar solution Synthetic Metals 162 (2012) 728-734.

[25] Y. Tao, H. Cheng, W. Zheng, Z. Zhang, Electrosynthesis and characterizations of a multielectrochromic copolymer based on pyrrole and 3 , 
4-ethylenedioxythiophene, Journal of Applied Polymer Science 127 (2013) 636-642.

[26] A.S. Sarac, G. Sönmez, F.C. Cebeci, Electrochemical synthesis and structural studies of polypyrroles, poly(3,4-ethylenedioxythiophene)s and copolymers of pyrrole and 3,4-ethylenedioxythiophene on carbon fibre microelectrodes J, Applied Electrochem 33 (2003) 295-301.

[27] S. Tarkuc, E. Sahmetlioglu, C. Tanyeli, I.M. Akhmedov, L. Toppare, Electrochromic properties of poly (1-(phenyl)-2,5-di(2-thienyl)-1H-pyrrole-co-3,4ethylenedioxy thiophene) and its application in electrochromic devices Optical Materials 30 (2008) 1489-1494.

[28] A.S. Ribeiro, d.A.U. Silva, M. Navarro, J. Tonholo, Electrochromism of dinitrobenzoyl derivatised polypyrrole films deposited on ITO/glass electrodes, Electrochimica Acta 51 (2006) 4892-4896.

[29] A.J. Bard, L.R. Faulkner, Electrochemical Methods: Fundamentals and Applications, Wiley, New York, 2001.

[30] P.A. Christensen, A. Hamnett, Techniques and Mechanisms in Electrochemistry, Blackie Academic \& Professional (1994)

[31] G.A. Snook, A.S. Best, Co-deposition of conducting polymers in a room temperature ionic liquid J, Materials Chemistry 19 (2009) 4248-4254.

[32] J.L. Bredas, G.B. Street, Polarons, bipolarons and solitons in conducting polymers, Accounts of Chemical Research (1985) 309-315.

[33] R.S. Hutton, M. Kalaji, L.M. Peter, Frequency resolved transmittance measurements on polyaniline films, Journal of Electroanalytical Chemistry 270 (1989) 429-436.

[34] E.M. Genies, M. Lapkowski, Polyaniline films: electrochemical redox mechanisms, Synthetic Metals 24 (1988) 61-68.

[35] d.C.E. Rios, A. Viana Rosario, A. Flávia Nogueira, L. Micaroni, Electrochromic devices based on poly 3-methyl thiophene and various secondary electrochromic materials Solar Energy Materials and Solar Cells 94 (2010) 1338-1345.
[36] V. Ratautaite, A. Ramanaviciene, Y. Oztekin, J. Voronovic, Z. Balevicius, L. Mikoliunaite, A. Ramanavicius, Electrochemical satbility and repulsion of polypyrrole film, Colloids and Surfaces A: Physiochemical and Engineering Aspects 418 (2013) 16-21.

[37] S. Desai, R.L. Shepherd, P.C. Innis, P. Murphy, C. Hall, R. Fabretto, G.G. Wallace, Gel electrolytes with ionic liquid plasticiser for electrochropmic devices, Electrochim. Acta 56 (2011) 4408-4413.

[38] M. Deepa, A. Awadhia, S. Bhandari, S.L. Agrawal, Electrochromic performance of a poly(3, 4- ethylene dioxythiophene)-prussion blue device encompassing a free standing proton electrolyte film, Electrochimica Acta 53 (2008) $7266-7275$

[39] W.A. Gazotti, G. Casalbore-Miceli, A. Geri, M.A. De Paoli, A solid state electrochromic device based on two optically complementary conducting polymers, Advanced Materials 10 (1998) 60-64.

[40] K.C. Chen, C.Y. Hsu, C.W. Hu, K.C. Ho, A Complementary Electrochromic device based on prussian blue and and poly ( proDOT-Et $_{2}$ ) with high contrast and high coloration efficiency, Solar Energy Materials and Solar Cells 95 (2011) 2238-2245.

[41] B. Wang, J.S. Zhao, C.S. Cui, J.F. Liu, Q.P. He, Electrosynthesis and characterisation of an electrochromic material from poly(1, 4-bis(3-methylthiophene-2yl)benzene) and its application in electrochromic device, Solar Energy Materials and Solar Cells 98 (2012) 161-167.

[42] G.G. Min, S.B. Kim, S.M. Park, Electrochemistry of Conductive Polymers 48. electrochemical polymerization of 3,4-ethylenedioxythiophene in ionic liquids and propylene carbonate physical and analytical electrochemistry, Journal of the Electrochemical Society 158 (2011) F92-F99.

[43] P. Damlin, C. Kvarnstrom, A. Ivaska, Electrochemical synthesis and in situ spectroelectrochemical characterisation of poly(3,4-ethylenedioxythiophene), PEDOT, in room temperature ionic liquids, Journal of Electroanalytical Chemistry 570 (2004) 113-122. 